\title{
Raising the Age of Purchase and Use of Tobacco Product in Bangladesh: Benefits and Challenges in Protecting Youth from the Tobacco Epidemic
}

\author{
Pranay Lal', Arpita Mitra ${ }^{2}$, Amit Yadav ${ }^{1}$, Raju Sarkar ${ }^{2}$, Sven Gudmund \\ Hinderaker ${ }^{3}$, Nirmalya Mukherjee ${ }^{2 *}$
}

\begin{abstract}
Background: Tobacco use among young and adolescents is the biggest threat to public health globally. In Bangladesh, every one in 14 youth (13-15 years) uses tobacco in some form. While this problem is growing in the country, we estimate the underage initiation of tobacco use and present evidence that policy measures like increasing the age of purchase and use from the current 18 years to 21 years in the country backed with current tobacco control efforts and adopting vendor licensing will significantly reduce future tobacco burden. Method: We analysed the two rounds of nationally representative Global Adult Tobacco Survey (GATS) data: GATS-1 (2009-10) and GATS-2 (2016-17) and segregated the data for two categories of tobacco consumption (smokers and smokeless tobacco users) based on the age of initiation $(<18,18-21$ and $>21$ years). Consumption patterns were also analyaed by using the GATS-2 data. Projections from sub-national level analysis for youth initiating tobacco use before 21 years and change in the prevalence of overall underage tobacco users were calculated based on weighted value. Result: According to GATS-2, around $89 \%$ of current tobacco users initiated tobacco use into daily use before the age of 18 years in Bangladesh. Whereas, striking differences were observed (statistically significant) for the average age of initiation of smoking among smokers aged 20-34 increased from 17.4 in 2009 to 19.3 years; and 20.1 to 22 years for SLT. Moreover, more than $24 \%$ of them initiated into regular smoking before the age of 15 years. Conclusion: There is an increasing trends of tobacco initiation among the underage youth of Bangladesh. By increasing the age of access, sale, purchase, and use of tobacco from current 18 years to 21 years will significantly reduce youth initiation and taper down the overall adult tobacco use prevalence over the long run in Bangladesh.
\end{abstract}

Keywords: Bangladesh- GATS- GYTS- MLA21- Tobacco

Asian Pac J Cancer Prev, 22, Progress of Tobacco Control in the South-East Asia Region Suppl, 65-70

\section{Introduction}

Tobacco is perhaps the only consumer product which causes disease and premature death both among its users and simultaneously among the non-users when used exactly as intended. Barring a few countries, tobacco use is the leading cause of preventable morbidity and premature mortality worldwide. Contrary to the tobacco industry's claims that it has put stringent voluntary measures to make tobacco products inaccessible to underage youth, global evidence suggests that $85 \%$ or more of all current tobacco users began their addiction before they were of legal age (WHO, 2021). One in every three adult and one in every 14 youth use tobacco in Bangladesh, which is responsible for killing one in every five persons in the country every year (WHO, 2018). While this problem is growing significantly in Bangladesh, there is limited published studies that look at the youth and adolescent prevalence and patter of tobacco use in the country.

The key ingredient that makes tobacco highly addictive is nicotine. Underage users lose their free will to nicotine addiction to stop or reduce the urge to consume tobacco products. The onset of addiction in a susceptible adolescent can begin after smoking as few as 12 cigarettes and sometimes after only a single cigarette (Scragg et al., 2008), become nicotine dependent even if smoking one or two cigarettes in a month (DiFranza et al., 2007) and significantly lower the chances of quitting or seeking cessation support (Chen et al., 1998). Neurobiological evidence suggests that initiating tobacco use until the age of 21 years, or perhaps 25 years, makes youths vulnerable to developing a lifelong addiction (van der Eijk et al., 
2021).

In order to curb the tobacco epidemic, an important approach has emerged globally by increasing the age of purchase and use from 18 to 21 years, termed minimum legal age of 21 years (MLA21, also labelled Tobacco21 in the US). There is significant literature starting from the mid-1980s which shows the tobacco industry acknowledging the powerful potential effect of raising the minimum age to purchase and use in the future on their profits. As per the internal tobacco industry documents produced during litigation between US states and the seven major tobacco industry organizations (later termed as the Master Settlement Agreement), a Phillip Morris memo, stated, "raising the legal minimum age for cigarette purchase (from 18) to 21 could gut our key young adult market" (Philip Morris). There is ample precedence that age restrictions work (Ahammed et al., 2021). Age restrictions are well-established and denormalize youths access to sin goods like alcohol, gambling, gun use, underage driving, and the use of drugs and dangerous substances.

Given that adolescents and youth make up a significant part of the population of Bangladesh (approximately amounting to $1 / 3$ rd of the country's total population) it is important to protect this majority of the population from falling into the trap of tobacco use and nicotine addiction. It is with this intention both WHO FCTC and the tobacco control legislation of Bangladesh prohibit sale of tobacco products to and by minors (person below the age of 18 years). However, keeping with the global best practices and to accelerate the reduction in tobacco use among adolescents and youth in the country, it is imperative to increase the age to 21 years.

This study intends to estimate the underage initiation of tobacco use in Bangladesh, and present evidence that a policy measure which increases the age of purchase and use from the current 18 years to 21 years in the country will help in reducing the future tobacco burden in the country.

\section{Materials and Methods}

The two rounds of nationally representative Global Adult Tobacco Survey data (GATS-1, 2009-10; and GATS-2, 2016-17) for Bangladesh were analyzed for the purpose of the study. The data were desegregated into two categories of tobacco consumption (smokers and chewing tobacco users) at the age initiation $(<18,18-21$ and $>21$ years). The consumption patterns found during the time of the Global Adult Tobacco Survey-2 (current daily, current less than daily, and former and ever users) were studied to draw the inference relating to the initiation of tobacco use before 21 years and change in the prevalence of overall underage tobacco users between two GATS datasets.

\section{Results}

GATS-2 in 2017 has estimated that 37.8 million adults (or 35.3\%, those of age and above the age of 15 years) consume some form of tobacco in Bangladesh (Institute of Medicine, 2015). Of these, 19.2 million (18\%) are smokers, and most are cigarette smokers $(14 \%$, or 15 million). Nearly $20.6 \%$ (or 22 million) chew tobacco, and $9.3 \%$ are dual users, i.e. they smoke and chew some form of tobacco. Tobacco use prevalence remains higher among men of older age, poor, less educated, rural and those who live in the slum and in tribal communities along particularly along the eastern border of the country. The largest burden of tobacco use is borne by disadvantaged groups, but the overall marginal decline must be viewed due to growth in income and greater purchasing power which has encouraged users to shift from bidis and khoinee (and other smokeless forms of tobacco, SLT) to more expensive products like cigarettes. Although all tobacco sales to those younger than 21 years account for just $6 \%$ of total tobacco sales in Bangladesh, it adds to the cohort of all future lifelong tobacco users. About $89 \%$ of current tobacco users initiated into daily use before the age of 18 years, and $99 \%$ before age 25 years, according to GATS- 2 .

The three waves of the Global Youth Tobacco Survey (GYTS-2004, 2007, 2013) conducted in Dhaka, Bangladesh in 2004, 2007, and 2013 had shown a secular trend in cigarette smoking among adolescent boys (from 2.3 to 3.0 to $2.1 \%$ ). Compared to this, the more comprehensive GATS-2 (2017) found that while there is a steady decline in most indicators of tobacco use in Bangladesh, it is not so among the youth.

One-third of Bangladesh's population is under the age of 15 years, and just $5 \%$ are aged 65 and over. The population growth, though lower than in previous decades, is around $1 \%$ and is expected to decline further. Yet, it is the youth of Bangladesh that will drive its prosperity, and the tobacco industry would like to increase its users as incomes grow. GATS-1 and GATS-2 show that Bangladesh has made commendable progress in tobacco control which is largely attributable to the strong implementation of tobacco control laws. The average age of initiation of smoking among smokers aged 20-34 increased from 17.4 in 2009 to 19.3 years; and 20.1 to 22 years for SLT; both these are statistically significant. Yet more than $24 \%$ initiated into regular smoking before the age of 15 years. Nearly $68 \%$ of smokers (Table 1 ) and more than $28 \%$ SLT users (Table 2) initiate before or until the age of 21 years.

Results of GATS-2 from 2017 show that the variation among divisions with higher tobacco use prevalence (Mymensingh, Sylhet, Barishal, Rangpur and Khulna) also have a lower mean age of initiation and have a higher prevalence among underage users compared to the national mean.

Smokeless tobacco and cigarettes show near secular trends in the age of initiation and prevalence rates between divisions, gender, place of residence, education and economic classes, suggesting that there is uniform behaviour in experimentation and uptake of tobacco use. The mean age of initiation is 18.8 years in Bangladesh, while in India it is 17.8 and in Pakistan 18.7. Among current male daily smokers aged $20-34,8.7 \%$ started smoking before they attained the age of 15 years, $14.4 \%$ began smoking before they were $16,30.1 \%$ initiated between 17 and 18 , and $46.8 \%$ began smoking after their twentieth birthday. The age of initiation for smoking for males is 19.3 years. Urban smokers initiate sooner (18.9 

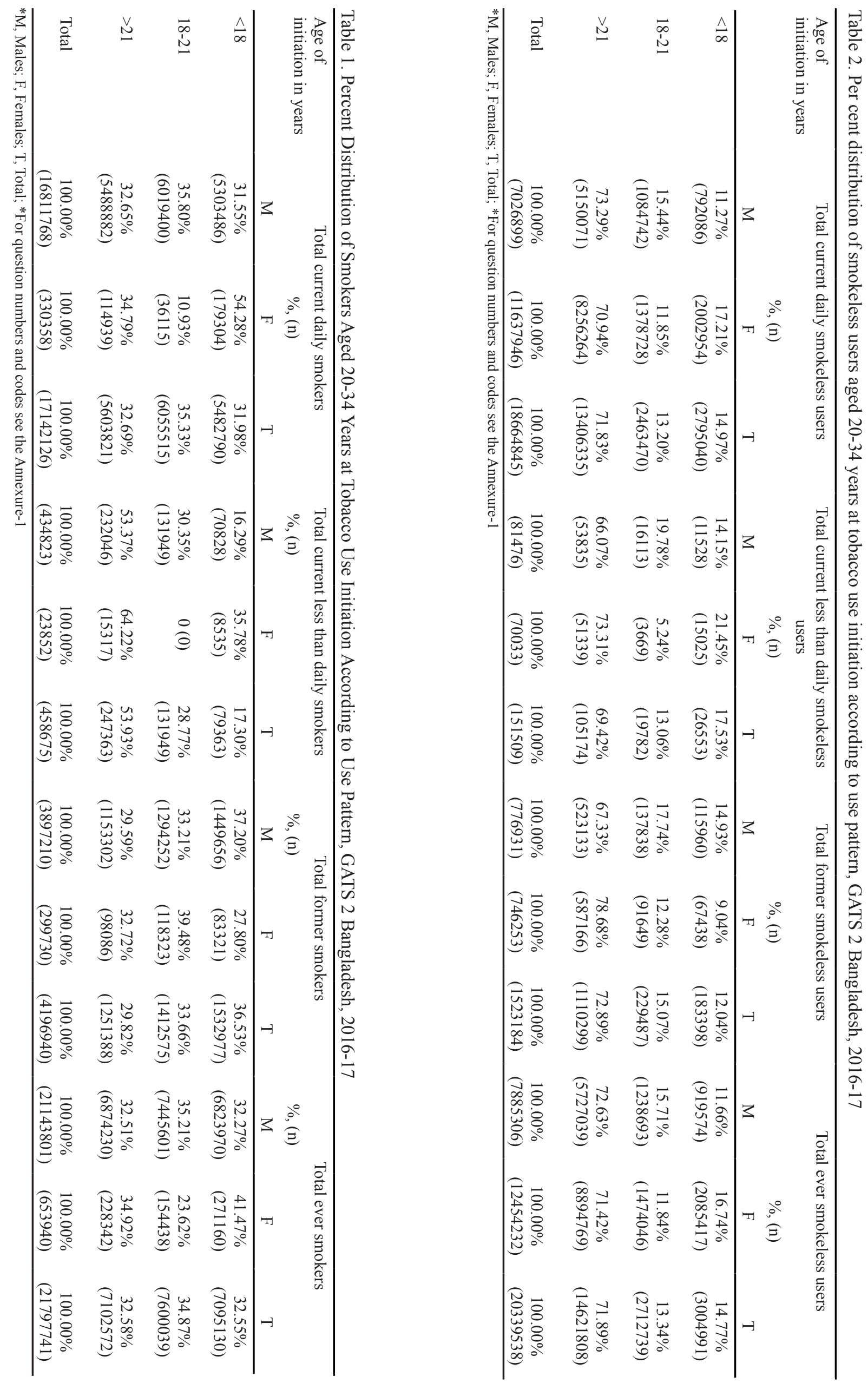
years) compared to rural smokers (19.4). Education and wealth show modest changes in prevalence, suggesting that the initiation behaviour is ubiquitous and pervasive. The mean age of initiation in four eastern divisions (Sylhet 18, Chattogram 18.1. Mymensingh 18.4, Barishal 18.9) is lower than the national mean (of 19.3 years), while four western divisions (Rajshahi 19.5, Dhaka 19.7, Rangpur and Khulna 20.1 years). Urban-rural differences between and across divisions are marginal, suggesting that the ease of access and affordability influence this uniform age of initiation.

Youths continue to be attracted to tobacco products. Between GATS1 and 2, tobacco advertisement, promotion and sponsorship increased for SLT; quit efforts have decreased across all tobacco forms despite increased advice from healthcare providers; median cigarette numbers increased from 6.4 to 7.6 sticks.

\section{Discussion}

Benefits of raising the age to 21 years for sale, purchase and use

In any given year, there are an estimated 10.1 million underage tobacco users (7.1 million smokers and 3 million SLT users) in Bangladesh who begin experimenting and eventually become lifelong users of tobacco. An additional 10.3 million youths (7.6 million smokers and 2.7 million SLT users between the age of 18 to 21 years) could be saved from tobacco addiction if an MLA21 policy had been in place in Bangladesh. Effectively, youth make for nearly one-third of Bangladesh's current tobacco users, and will add up to become lifelong users of adult tobacco users. Since less than $4 \%$ lifelong users quit tobacco, nearly $52 \%$ of them would die prematurely of a tobacco attributable disease. Such premature deaths not only impoverish households and communities, but dent human development indicators due to persistence of disease, and lowering life expectancy goals.

The global tobacco industry has intensified marketing in deadly products to the developing world, and Bangladesh is among its easy targets. Bangladesh's tobacco sector comprises highly organized cigarette companies, led by British American Tobacco, which holds $65.4 \%$ of the cigarette market by volume, and Dhaka Tobacco Industries (part of the Akij Group), with $20.8 \%$ of the cigarette market. Philip Morris International distributes its products in Bangladesh through Dhaka Tobacco Industries, and Japan Tobacco Inc boosted its presence by acquiring Akij Group in 2018. In 2020, 94.3 billion cigarettes were sold in Bangladesh, a 3\% year on year increase in volume (Euromonitor, 2020) The high rate of smoking before or by 21 years (Table 1) may be attributed to this huge multinational cigarette companies presence and their aggressive marketing in Bangladesh and call for urgent and comprehensive policy requiring MLA21. The Government of Bangladesh is currently sending mixed messages by adopting a two-faced policy: on the one hand it is making reasonable progress in implementing global good practices like the MPOWER policy package and FCTC (Framework Convention on
Tobacco Control) guidelines, but on the other hand it is doing little to deter new investments in the tobacco sector or reducing tobacco advertising, promotion and sponsorship. Successful models suggest that a suite of strategies are needed; that is, target informal sale and distribution networks which are backed with stronger enforcement of age of purchase at the point of sales, coupled with high retail price, strong graphic health warnings and advertisement bans (Farber et al., 2015). Decreasing youth smoking rates have important present and future public health benefits and outcomes. In 2015, the Institute of Medicine present evidence to policymakers stating that a nationwide Tobacco 21 policy could potentially reduce youth smoking initiation by $25 \%$ and lead to a $12 \%$ decrease in overall smoking rates in the US. The committee report estimated that the policy would avert 4.2 million years of life lost to smoking in American children alive today (Institute of Medicine, 2015). If implemented well, the MLA21 policy can help reduce tobacco use prevalence among more vulnerable groups (Grube et al., 2021). One study found that Tobacco 21 laws were more effective at reducing youth use than raising cigarette taxes (Bryan et al., 2021). Raising the minimum legal age to purchase tobacco products to 21 years is highly supported by both the smoking and the people exposed to smoke in public. A 2015, a US CDC study showed that $75 \%$ of the American public, including $70 \%$ of current smokers, supported a minimum tobacco purchase age of 21 (Winickoff et al., 2016). In 2020, $76 \%$ Australians supported the MLA21 initiative, while Tasmania, the first state to adopt MLA21, 78\% people supported it (Friedman et al., 2019).

Evidence from across the states of the US has shown that raising the age of purchase and consumption of alcohol in the 1980 s to 21 years not only reduced teen drinking by 34\% (DeJong et al., 2014), but also reduced the number of drunk driving deaths and other risky behaviours (McCartt et al., 2010). The earliest evaluated evidence of benefits of MLA21 was done in Needham, Massachusetts, USA in 2005, which did a follow-up survey five years after implementation and found that the smoking rates fell among high school youth from 13\% to $7 \%$ compared with neighbouring cities (Kessel et al., 2016). New York became the first major city to enact MLA21 in 2013, followed by states like Hawaii and California. Currently, nearly 19 states and 540 cities is covered by a MLA21 policy in the US. Globally Ethiopia (2019), Uganda (2016), Mongolia (2013), Honduras (2010), Sri Lanka (2017), The Philippines (2020) and Singapore (January 2021) have introduced nation-wide MLA21 policy. The state of Goa in India In any given year, there are an estimated 10.1 million underage tobacco users (7.1 million smokers and 3 million SLT users) in Bangladesh who begin experimenting and eventually become lifelong users of tobacco. An additional 10.3 million youths ( 7.6 million smokers and 2.7 million SLT users between the age of 18 to 21 years) could be saved from tobacco addiction if an MLA21 policy had been in place in Bangladesh. Effectively, youth make for nearly one-third of Bangladesh's current tobacco users, and 
will add up to become lifelong users of adult tobacco users. Since less than $4 \%$ lifelong users quit tobacco, nearly $52 \%$ of them would die prematurely of a tobacco attributable disease. Such premature deaths not only impoverish households and communities, but dent human development indicators due to persistence of disease, and lowering life expectancy goals.

The global tobacco industry has intensified marketing in deadly products to the developing world, and Bangladesh is among its easy targets. Bangladesh's tobacco sector comprises highly organized cigarette companies, led by British American Tobacco, which holds $65.4 \%$ of the cigarette market by volume, and Dhaka Tobacco Industries (part of the Akij Group), with 20.8\% of the cigarette market. Philip Morris International distributes its products in Bangladesh through Dhaka Tobacco Industries, and Japan Tobacco Inc boosted its presence by acquiring Akij Group in 2018. In 2020, 94.3 billion cigarettes were sold in Bangladesh, a 3\% year on year increase in volume (Euromonitor, 2020) The high rate of smoking before or by 21 years (Table 1) may be attributed to this huge multinational cigarette companies presence and their aggressive marketing in Bangladesh and call for urgent and comprehensive policy requiring MLA21. The Government of Bangladesh is currently sending mixed messages by adopting a two-faced policy: on the one hand it is making reasonable progress in implementing global good practices like the MPOWER policy package and FCTC (Framework Convention on Tobacco Control) guidelines, but on the other hand it is doing little to deter new investments in the tobacco sector or reducing tobacco advertising, promotion and sponsorship. Successful models suggest that a suite of strategies are needed; that is, target informal sale and distribution networks which are backed with stronger enforcement of age of purchase at the point of sales, coupled with high retail price, strong graphic health warnings and advertisement bans (Farber et al., 2015). Decreasing youth smoking rates have important present and future public health benefits and outcomes. In 2015, the Institute of Medicine present evidence to policymakers stating that a nationwide Tobacco 21 policy could potentially reduce youth smoking initiation by $25 \%$ and lead to a $12 \%$ decrease in overall smoking rates in the US. The committee report estimated that the policy would avert 4.2 million years of life lost to smoking in American children alive today (Institute of Medicine, 2015). If implemented well, the MLA21 policy can help reduce tobacco use prevalence among more vulnerable groups (Grube et al., 2021). One study found that Tobacco 21 laws were more effective at reducing youth use than raising cigarette taxes (Bryan et al., 2021). Raising the minimum legal age to purchase tobacco products to 21 years is highly supported by both the smoking and the people exposed to smoke in public. A 2015, a US CDC study showed that $75 \%$ of the American public, including $70 \%$ of current smokers, supported a minimum tobacco purchase age of 21 (Winickoff et al., 2016). In 2020, $76 \%$ Australians supported the MLA21 initiative, while Tasmania, the first state to adopt MLA21, 78\% people supported it (Friedman et al., 2019).

Evidence from across the states of the US has shown that raising the age of purchase and consumption of alcohol in the 1980 s to 21 years not only reduced teen drinking by $34 \%$ (DeJong et al., 2014), but also reduced the number of drunk driving deaths and other risky behaviours (McCartt et al., 2010). The earliest evaluated evidence of benefits of MLA21 was done in Needham, Massachusetts, USA in 2005, which did a follow-up survey five years after implementation and found that the smoking rates fell among high school youth from $13 \%$ to $7 \%$ compared with neighbouring cities (Kessel et al., 2016). New York became the first major city to enact MLA21 in 2013, followed by states like Hawaii and California. Currently, nearly 19 states and 540 cities is covered by a MLA21 policy in the US. Globally Ethiopia (2019), Uganda (2016), Mongolia (2013), Honduras (2010), Sri Lanka (2017), The Philippines (2020) and Singapore (January 2021) have introduced nation-wide MLA21 policy. The state of Goa in India

\section{Author Contribution Statement}

The authors confirm contribution to the paper as follows: Conceptualized the study: Mr. Pranay Lal. First draft of Manuscript developed: Mr. Pranay Lal, Arpita Mitra, Amit Yadav, Nirmalya Mukherjee. Review and editing the draft: Pranay Lal, Amit Yadav, Sven Gudmund Hinderaker, Nirmalya Mukherjee. Data analysis: Mr. Pranay Lal, Arpita Mitra, Raju Sarkar, Sven Gudmund Hinderaker. Manuscript finalization: Mr. Pranay Lal, Arpita Mitra, Amit Yadav, Raju Sarkar, Sven Gudmund Hinderaker, Nirmalya Mukherjee.

\section{Acknowledgements}

The publishing cost was provided by WHO office in South-East Asia.

\section{References}

Ahammed T, Ahmed NU, Uddin M (2021). Changes in prevalence, and factors associated with tobacco use among Bangladeshi school students: evidence from two nationally representative surveys. BMC Public Health, 579.

Bryan C, Hansen B, McNichols D, Sabia JJ (2021). Do state tobacco 21 laws work? NBER Working Paper 28173. April 2021.

Chen J, Millar WJ (1988). Age of smoking initiation: implications for quitting. Health Rep, 9, 39-46.

DeJong W, Blanchette J (2014). Case closed: research evidence on the positive public health impact of the age 21 minimum legal drinking age in the United States. J Stud Alcohol Drugs Suppl, 75, 108-15.

DiFranza JR, Savageau JA, Fletcher K, et al (2007). Symptoms of tobacco dependence after brief intermittent use: the Development and Assessment of Nicotine Dependence in Youth-2 study. Arch Pediatr Adolesc Med, 161, 704-10.

Euromonitor. Tobacco in Bangladesh. Sep 2020. Accessed from https://www.euromonitor.com/bangladesh.

Farber HJ, Groner J, Walley S, Nelson K (2015). Section on Tobacco Control. Protecting children from tobacco, nicotine, and tobacco smoke. Pediatrics, 136, 1439-67.

Friedman et al. Addiction (1). (2019). Accessed from https://www.smokefreetasmania.com/faq-2/from:

Asian Pacific Journal of Cancer Prevention, Vol 22 
https://industrydocuments.library.ucsf.edu/tobacco/ docs/\#id=zswh0127.

Global Adult Tobacco Survey 2009-10 (GATS-1). Bangladesh Report 2017. Accessed from https://www.cdc.gov/tobacco/ global/index.htm.

Global Adult Tobacco Survey 2015-16 (GATS-2). Bangladesh Report 2017. Accessed from https://ntcc.gov.bd/ntcc/uploads/ editor/files/GATS\%20Report\%20Final-2017_20\%20MB. PDF.

Global Youth Tobacco Survey (GYTS). Bangladesh Report 2004, 2007 \& 2013. Accessed from https://www.cdc.gov/ tobacco/global/index.htm.

Grube JW, Lipperman-Kreda S, García-Ramírez G, et al (2021). California's tobacco 21 minimum sales age law and adolescents' tobacco and nicotine use: differential associations among racial and ethnic groups. Tob Control, 2021, doi: 10.1136/tobaccocontrol-2020-056219.

Institute of Medicine. Public health implications of raising the minimum age of legal access to tobacco products. Washington, DC: National Academies Press; 2015.

Kessel, Schneider S, Buka SL, et al (2016). Community reductions in youth smoking after raising the minimum tobacco sales age to 21. Tob Control, 25, 355-9.

McCartt AT, Hellinga LA, Kirley BB (2010). The effects of minimum legal drinking age 21 laws on alcohol-related driving in the United States. J Safety Res, 41, 173-81.; and Institute for Highway Safety. Fatality facts 2017: teenagers. Highway Loss Data Institute; December 2018. www.iihs. org/topics/fatality-statistics/detail/teenagers (accessed 23 July 2021).).

Philip Morris. Discussion draft of sociopolitical strategy. [Accessed 2021 Aug 5]. Available from: https://industrydocuments. library.ucsf.edu/tobacco/docs/\#id=zswh0127.

Scragg R, Wellman RJ, Laugesen M, DiFranza JR (2008). Diminished autonomy over tobacco can appear with the first cigarettes. Addict Behav, 33, 689-98.

Van der Eijk Y, Chen JI (2020). Case for raising the minimum legal age of tobacco sale to 25. Tob Control, 2021. doi: 10.1136/tobaccocontrol-2020-055964.

Winickoff JP, McMillen R, Tanski S, et al (2016). Public support for raising the age of sale for tobacco to 21 in the United States. Tob Control, 25, 284-8.

World Health Organization (2018). Bangladesh Factsheet (2018). Accessed from https://apps.who.int/iris/bitstream/ handle/10665/272670/ wntd_2018_bangladesh_ fs.pdf?sequence $=1$.

World Health Organization (2021). WHO Report on the Global Tobacco Epidemic, 2021: address new and emerging products. Accessed from https://apps.who.int/iris/rest/ bitstreams/1359088/retrieve(Accessed on 9 August 2021).

\section{๑ळब}

This work is licensed under a Creative Commons AttributionNon Commercial 4.0 International License. 